OPEN ACCESS

Edited by:

Xiaojuan Feng,

Institute of Botany, (CAS), China

Reviewed by:

Jun-Jian Wang,

Southern University of Science and

Technology, China

Hongyan Bao,

Xiamen University, China

*Correspondence:

Ding $\mathrm{He}$

dinghe@zju.edu.cn

Specialty section:

This article was submitted to

Biogeoscience,

a section of the journal

Frontiers in Earth Science

Received: 20 April 2021 Accepted: 28 June 2021

Published: 08 July 2021

Citation:

Li P, Zhao C, Liu K, Xiao X, Wang Y,

Wang $Y$ and He D (2021)

Anthropogenic Influences on Dissolved

Organic Matter in Three Coastal Bays,

North China.

Front. Earth Sci. 9:697758.

doi: 10.3389/feart.2021.697758

\section{Anthropogenic Influences on Dissolved Organic Matter in Three Coastal Bays, North China}

\author{
Penghui $\mathrm{Li}^{1,2}$, Chen $\mathrm{Zhao}^{3}$, Ke $\mathrm{Liu}^{4}$, Xiaotong Xiao ${ }^{4}$, Yujue Wang ${ }^{5}$, Yuntao Wang ${ }^{6}$ and \\ Ding $\mathrm{He}^{3,6 *}$
}

${ }^{1}$ School of Marine Sciences, Sun Yat-Sen University, Zhuhai, China, ${ }^{2}$ Southern Marine Science and Engineering Guangdong Laboratory (Zhuhai), Zhuhai, China, ${ }^{3}$ Organic Geochemistry Unit, School of Earth Sciences, Zhejiang University, Hangzhou, China, ${ }^{4}$ Frontiers Science Center for Deep Ocean Multispheres and Earth System, and Key Laboratory of Marine Chemistry Theory and Technology, Ministry of Education, Ocean University of China, Qingdao, China, ${ }^{5}$ State Key Laboratory of Estuarine and Coastal Research, East China Normal University, Shanghai, China, ${ }^{6}$ State Key Laboratory of Satellite Ocean Environment Dynamics, Second Institute of Oceanography, Ministry of Natural Resources, Hangzhou, China

Coastal bays bear anthropogenic influence strongly, and thus dissolved organic matter (DOM) in coastal bays, which is an important component of global carbon cycling, could be heavily affected by anthropogenic inputs. Utilizing absorbance, fluorescence spectroscopy, and stable carbon isotope $\left(\delta^{13} \mathrm{C}\right)$, this study analyzed the characteristics and distribution of DOM in three coastal bays (Jiaozhou Bay, Sishili Bay, and Taozi Bay), located in North China. The results showed that there was always a high concentration of DOM near the river mouth in all three bays and the DOM concentration decreased along the salinity gradient in Jiaozhou Bay, indicating the riverine inputs are the main factor that causes the variation of DOM in these coastal bays. The effects of inflowing rivers on DOM in coastal bays differed with their watershed characteristics (i.e., agricultural/urban). In addition, humic-like DOM components were found to be positively correlated with the apparent oxygen utilization, suggesting microbial activities could contribute to the DOM in this region. There was generally a higher averaged concentration of fluorescent DOM in surface water than that in bottom water in Jiaozhou Bay. In contrast, higher humic-like DOM was found in bottom water than that in surface water in Sishili Bay and Taozi Bay, which could be attributed to aquaculture activities and biological production. Moreover, photodegradation/photobleaching, dumping, and sewage discharge had their effects on DOM in coastal bays. This study demonstrates that DOM in coastal bays is regulated by multiple sources (rivers, aquaculture, dumping, and sewage) and processes (biological production and photodegradation), and anthropogenic activities have their influences on optical and isotopic characteristics of DOM in coastal bays.

Keywords: dissolved organic matter, coastal bay, fluorescence, anthropogenic influence, stable carbon isotope

\section{INTRODUCTION}

Estuarine and coastal areas link the land and the sea, thus playing important roles in carbon transport between these two largest carbon pools (Cai, 2011). Large amounts of terrestrial organic matter are transported to estuaries and coastal areas by rivers (Bianchi, 2011). Moreover, about $40 \%$ of the world's population lives within $100 \mathrm{~km}$ of the coast. Anthropogenic-derived nutrients and organic 
matter have been released to coastal areas, exerting a strong influence on aquatic ecosystems (eutrophication, algal bloom, hypoxia, etc.,) and carbon cycling (Cai et al., 2011). Despite the importance of coastal areas in global carbon cycling, coastal areas received less attention than estuarine regions (Li et al., 2015; He et al., 2020).

Dissolved organic matter (DOM) is the largest organic carbon pool in the ocean and has drawn increasing attention in the past decades (Hansell, 2015). Meanwhile, as the most reactive carbon pool, DOM could be significantly affected by anthropogenic activities and multiple biogeochemical processes (e.g., biodegradation and photodegradation) ( $\mathrm{Li}$ et al., 2015; He et al., 2020; Lønborg et al., 2020). Previous studies have shown that in estuarine and coastal areas, riverine input would be one of the most important sources of DOM (Raymond and Bauer, 2001; Li et al., 2015; Guéguen et al., 2016). Besides, the input of riverine nutrients could stimulate primary production and thus influence the quantity and quality of DOM (Zhang and Yang, 2013; Asmala et al., 2018). Moreover, most marine aquaculture pools locate in coastal areas, releasing DOM into nearby waters (Zhao et al., 2001; Mahmood et al., 2017). Compared to large river estuaries, the water retention time in coastal areas, especially coastal bays, is relatively long due to hydrodynamic and geomorphological characteristics, allowing coastal areas to act as "reactors" as well as "pipes" of DOM (Casas-Ruiz et al., 2017; Liu et al., 2019).

Considering its complexity, multiple methods have been developed to study the quantity, quality, sources, and fates of DOM (Moran et al., 2016). Due to high sensitivity, fast response, easy use, and low cost, spectroscopic methods have been widely utilized to study DOM in the past several decades (Coble et al., 2014; Li and Hur, 2017). The ultraviolet-visible (UV-Vis) absorbance spectroscopy has been used to indicate the abundance and property of chromophoric DOM (CDOM) (Li and Hur, 2017). With high sensitivity, fluorescence spectroscopy has been extensively utilized to quantify and qualify DOM. Combining with parallel factor analysis (PARAFAC), fluorescence excitation-emission matrix (EEM) could be separated into independent fluorescent components. Besides, several indices were developed to indicate the source and property of fluorescent DOM (FDOM) (Zsolnay et al., 1999; McKnight et al., 2001; Cory and McKnight, 2005; Huguet et al., 2009). In addition to spectroscopic methods, stable carbon isotope analysis was also used to differentiate DOM from different sources (Cawley et al., 2012).

Due to rapid socio-economic development, most coastal areas in China are under increasing anthropogenic pressure. A significant fraction of treated domestic sewage has been discharged into coastal areas, increasing the concentration of organic matter and nutrients, and thus resulting in eutrophication and hypoxia (Strokal et al., 2014; Wang et al., 2018). Besides, heavy aquaculture activities occur in coastal areas, influencing the DOM in coastal bays (Li et al., 2018), and also intensifying eutrophication and hypoxia (Li et al., 2018; Liang et al., 2018; Zhang et al., 2018). One recent study shows that the concentration of humic-like DOM could be elevated in the kelp mariculture zone in Ailian Bay, China (Li et al., 2018). In addition, both eutrophication and hypoxia have a non- negligible effect on DOM dynamics in coastal areas (Zhang and Yang, 2013; Asmala et al., 2018; Zhang et al., 2018; Zhao et al., 2021). For example, Asmala et al. (2018) found that eutrophication could lead to the accumulation of recalcitrant DOM in coastal environments. Besides, hydrodynamics and geomorphology in coastal areas would affect the water exchange, thus exerting their effects on DOM dynamics (Jennerjahn and Ittekkot, 2002).

Coastal areas in Shandong Province are seriously affected by anthropogenic activities due to the fast development of the economy and aquaculture (Liang et al., 2018). Therefore, three coastal bays (Jiaozhou Bay, Sishili Bay, and Taozi Bay) in Shandong Province were selected to explore anthropogenic influences on DOM in coastal areas. Combining UV-Vis absorbance spectroscopy, fluorescence spectroscopy, and stable carbon isotope, this study aims to 1) investigate the spatial variations of DOM in coastal bays; 2) elucidate the sources of DOM in coastal bays; 3) evaluate the effects of anthropogenic activities on DOM in coastal bays.

\section{MATERIALS AND METHODS}

\section{Study Area}

All three bays (Jiaozhou Bay, Sishili Bay, and Taozi Bay) in this study were situated in Shandong Province of northern China, and on the western coast of the Yellow Sea (Figure 1; Schlitzer, 2018). As a semi-closed bay, Jiaozhou Bay has a narrow mouth of $2.5 \mathrm{~km}$ and a shallow average depth of $7 \mathrm{~m}$. Jiaozhou Bay is surrounded by Qingdao City and more than 10 rivers flow into the bay. On the western coast, Dagu River, Yang River, and Lianwan River flow into the bay. On the eastern coast, more urban rivers (Moshui River, Baisha River, Loushan River, Licun River, Haipo River, etc.,) flow into the bay, and these rivers served as sewage discharge channels for many years (Hu et al., 2020). Besides, many marine aquaculture pools (e.g., fish and shellfish) locate at the western area of Jiaozhou Bay.

Compared with Jiaozhou Bay, Sishili Bay, and Taozi Bay are relatively open bays near Yantai City, and are divided by Zhifu Island. Guangdang River, Xinan River, and Xiaoyuniao River flow into Sishili Bay. Jia River, Huangjin River, and Baiyin River flow into Taozi Bay. Meanwhile, both Sishili Bay and Taozi Bay are important marine aquaculture (e.g., scallop) areas in Shandong Province, China.

The study area experiences subtropical dry and wet seasons, and the wet season starts from June to September. In most years, there is the highest precipitation in July and August, therefore most of the rivers in our study have their highest discharge during this period.

\section{Sample Collection and Measurement}

Water samples were collected at the surface layer $(1 \mathrm{~m}$ below the water surface), chlorophyll a (Chl-a) maximum layer (Chl-a Max), and bottom layer ( $2 \mathrm{~m}$ above the seafloor) in Jiaozhou Bay, Sishili Bay, and Taozi Bay during the wet season (July and August) of 2019. The samples were immediately filtered onboard using $0.2 \mu \mathrm{m}$ polycarbonate membranes (Millipore) and stored 


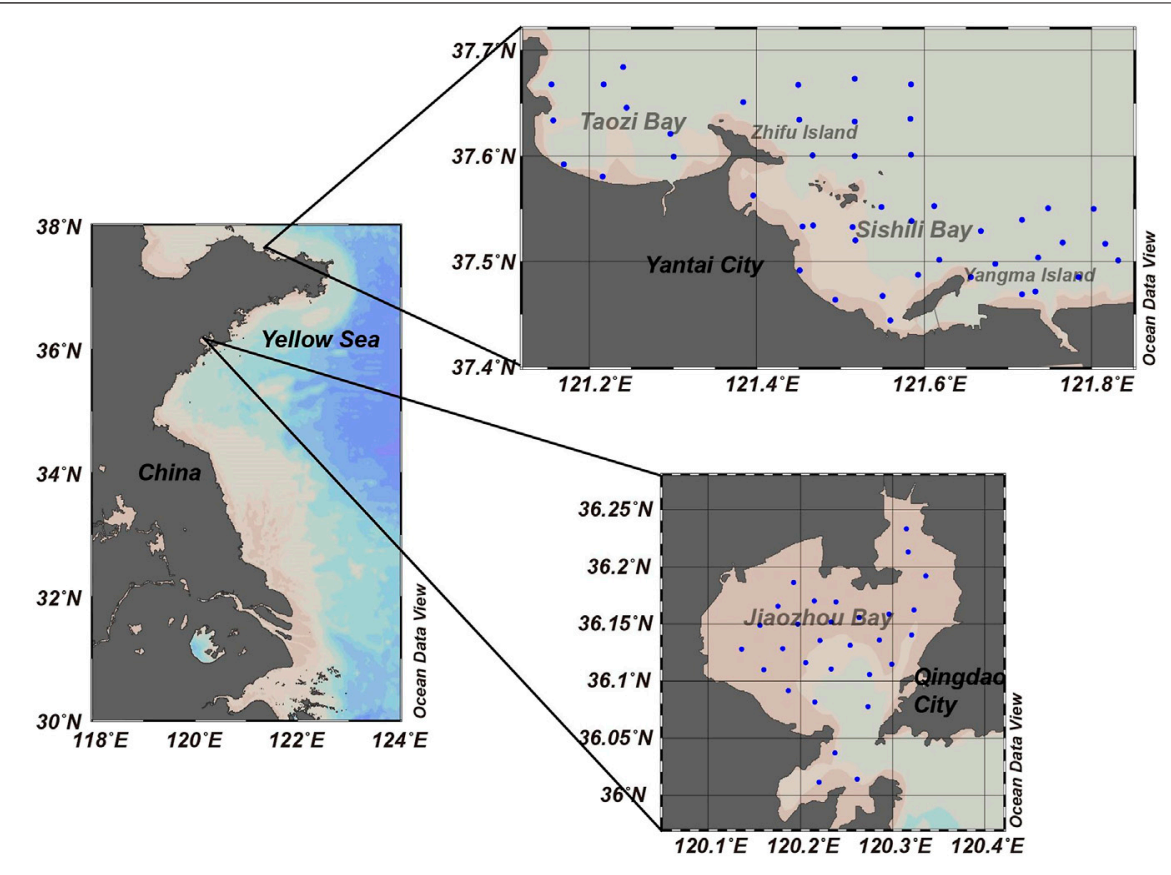

FIGURE 1 | Sampling sites (marked by blue circles) in Jiaozhou Bay, Sishili Bay, and Taozi Bay, China.

frozen at $-20^{\circ} \mathrm{C}$ before analysis. Temperature and salinity were obtained through a CTD (Conductivity, Temperature, Depth; SBE 25 plus) recorder (Seabird, United States). Dissolved oxygen (DO) concentration was obtained from CTD equipment on board. The DO sensor was calibrated against water sample analyses conducted by the Winkler titration method. Concentrations of Chl-a were measured following the method described by Arar and Collins (1997).

\section{Dissolved Organic Carbon and Physicochemical Parameters}

Dissolved organic carbon (DOC) and total dissolved nitrogen (TDN) were measured on a total organic carbon (TOC) analyzer equipped with a Total Nitrogen Module (TOC-L, Shimadzu, Japan). The stable carbon isotopic composition $\left(\delta^{13} \mathrm{C}\right)$ was measured based on solid-phase extracted DOM (SPE-DOM) on an isotope ratio mass spectrometer (Finnigan MAT 253, Thermo Scientific, United States). The solid-phase extraction of DOM was conducted using PPL cartridges (Agilent Bond Elut PPL, $200 \mathrm{mg}, 3 \mathrm{ml}$ ) according to the method developed by Dittmar et al. (2008). The stable carbon isotopic values are reported in $\delta^{13} \mathrm{C}$ notation (\%o) relative to the Vienna Pee Dee Belemnite with precision and accuracy within $0.2 \%$.

\section{Ultraviolet-visible Absorbance Spectra}

The UV-Vis absorbance and fluorescence spectra were determined on an Aqualog (Horiba) fluorescence spectrometer equipped with a $1 \times 1 \mathrm{~cm}$ quartz cuvette. The absorbance spectra were measured from 240 to $600 \mathrm{~nm}$ with an interval of $3 \mathrm{~nm}$. Absorbance spectra of milli-Q water were used as a reference and average absorbance between 580 to $600 \mathrm{~nm}$ was used for baseline correction. The absorption coefficient $\left(a_{351}\right)$ was calculated to quantify the CDOM abundance. The spectral slope $\left(\mathrm{S}_{275-295}\right)$ was calculated through the linear fitting of log-transformed absorption coefficient according to Helms et al. (2008) to indicate the source and quality of CDOM. The low $\mathrm{S}_{275-295}$ suggests that the DOM contains a high proportion of terrestrial-derived organic matter and $S_{275-295}$ would increase due to photobleaching (Fichot and Benner, 2012).

\section{Fluorescence Spectra}

The three-dimensional fluorescence spectra (excitation-emission matrices, EEMs) were scanned across $240-600 \mathrm{~nm}$ at $3 \mathrm{~nm}$ intervals for excitation wavelengths (Ex) and 248.1-825.1 nm at $3.7 \mathrm{~nm}$ intervals for emission wavelengths (Em). The integration time was $0.5 \mathrm{~s}$. Milli-Q water was scanned every day for blank subtraction and Raman normalization. All spectra were blank subtracted and corrected for inner-filter effect with the Horiba Aqualog software. Also, fluorescence index (FI, the ratio of the fluorescence intensity at 470 and $520 \mathrm{~nm}$ when $\mathrm{Ex}=370 \mathrm{~nm}$ ), biological index (BIX, the ratio of the fluorescence intensity at 380 and $430 \mathrm{~nm}$ when $\mathrm{Ex}=310 \mathrm{~nm}$ ), and humification index (HIX, the ratio of the sum fluorescence intensity in the $300-345 \mathrm{~nm}$ and $435-480 \mathrm{~nm}$ when $\mathrm{Ex}=254 \mathrm{~nm}$, and $\mathrm{Ex}=255 \mathrm{~nm}$ is used herein) were calculated based on fluorescence spectra to indicate the source and quality of DOM (Zsolnay et al., 1999; McKnight et al., 2001; Cory and McKnight, 2005; Huguet et al., 2009). The FI has a value of $\sim 1.55$ for microbially derived fulvic acid and $\sim 1.21$ for terrestrially derived fulvic acids (Cory et al., 2010). The BIX could indicate the contribution of autochthonous organic matter and the high BIX value suggests a high contribution of autochthonous organic matter 
TABLE 1 | Summary of physicochemical parameters in Jiaozhou Bay, Sishili Bay, and Taozi Bay (Mean \pm SD (Min-Max).

\begin{tabular}{|c|c|c|c|c|c|c|}
\hline Bay & $\begin{array}{l}\text { Sample } \\
\text { number }\end{array}$ & Salinity & Temperature $\left({ }^{\circ} \mathrm{C}\right)$ & Chl-a $\left(\mu \mathrm{g} \mathrm{L}^{-1}\right)$ & $\mathrm{DO}\left(\mu \mathrm{mol} \mathrm{L}{ }^{-1}\right)$ & TDN $\left(\mu \mathrm{mol} \mathrm{L} \mathrm{L}^{-1}\right)$ \\
\hline \multicolumn{7}{|l|}{ Jiaozhou } \\
\hline \multicolumn{7}{|l|}{ bay } \\
\hline Surface & 30 & $30.27 \pm 1.54(26.01-31.59)$ & $26.7 \pm 0.5(25.9-27.7)$ & $2.2 \pm 1.3(0.7-5.7)$ & $220.6 \pm 28.3(184.8-293.7)$ & $55.5 \pm 42.7(17.7-171.3)$ \\
\hline Chla-max & 1 & 31.38 & 26.2 & 9.0 & 249.6 & 34.2 \\
\hline Bottom & 15 & $31.09 \pm 0.47(29.82-31.55)$ & $26.2 \pm 0.2(26.0-26.6)$ & $2.1 \pm 1.6(0.7-6.3)$ & $205.1 \pm 27$ (168.8-261.6) & $36.1 \pm 16.3(16.9-72.9)$ \\
\hline \multicolumn{7}{|l|}{ Sishili bay } \\
\hline Surface & 35 & $31.66 \pm 0.12(31.24-31.92)$ & $25.0 \pm 1.4(22.3-27.2)$ & $1.5 \pm 2.3(0.2-12.9)$ & $214.0 \pm 20.6(149.0-237.3)$ & $20.4 \pm 4.7(15.4-34.9)$ \\
\hline Chla-max & 32 & $31.77 \pm 0.12(31.36-31.99)$ & $22.4 \pm 1.0(19.2-24.4)$ & $4.3 \pm 4.1(1.4-15.0)$ & $168.8 \pm 34.6(111.4-227)$ & $20.8 \pm 3.4(14.2-27.7)$ \\
\hline Bottom & 11 & $31.84 \pm 0.07(31.77-32.01)$ & $21.1 \pm 0.4(20.6-21.9)$ & $0.7 \pm 0.3(0.4-1.6)$ & $136.4 \pm 36.4$ (80.6-192.0) & $27 \pm 7.8(16.6-45.1)$ \\
\hline \multicolumn{7}{|l|}{ Taozi bay } \\
\hline Surface & 10 & $31.79 \pm 0.13(31.49-31.92)$ & $24.4 \pm 1.0(23-25.7)$ & $1.2 \pm 0.4(0.7-1.9)$ & $223.8 \pm 6.9$ (212.9-231.3) & $20.8 \pm 4(16-29.4)$ \\
\hline Chla-max & 6 & $31.88 \pm 0.06(31.77-31.95)$ & $22.5 \pm 0.3(22.0-23.0)$ & $2.5 \pm 0.7(2-3.8)$ & $207.9 \pm 22.3(164.4-223.9)$ & $21.9 \pm 3.7(18.1-28.7)$ \\
\hline Bottom & 4 & $31.79 \pm 0.04(31.74-31.83)$ & $22.5 \pm 0.4(22.1-22.7)$ & $3 \pm 1.2(1.7-3.9)$ & $210.9 \pm 6.7(205.7-218.5)$ & $26 \pm 4.7(23.2-31.4)$ \\
\hline
\end{tabular}
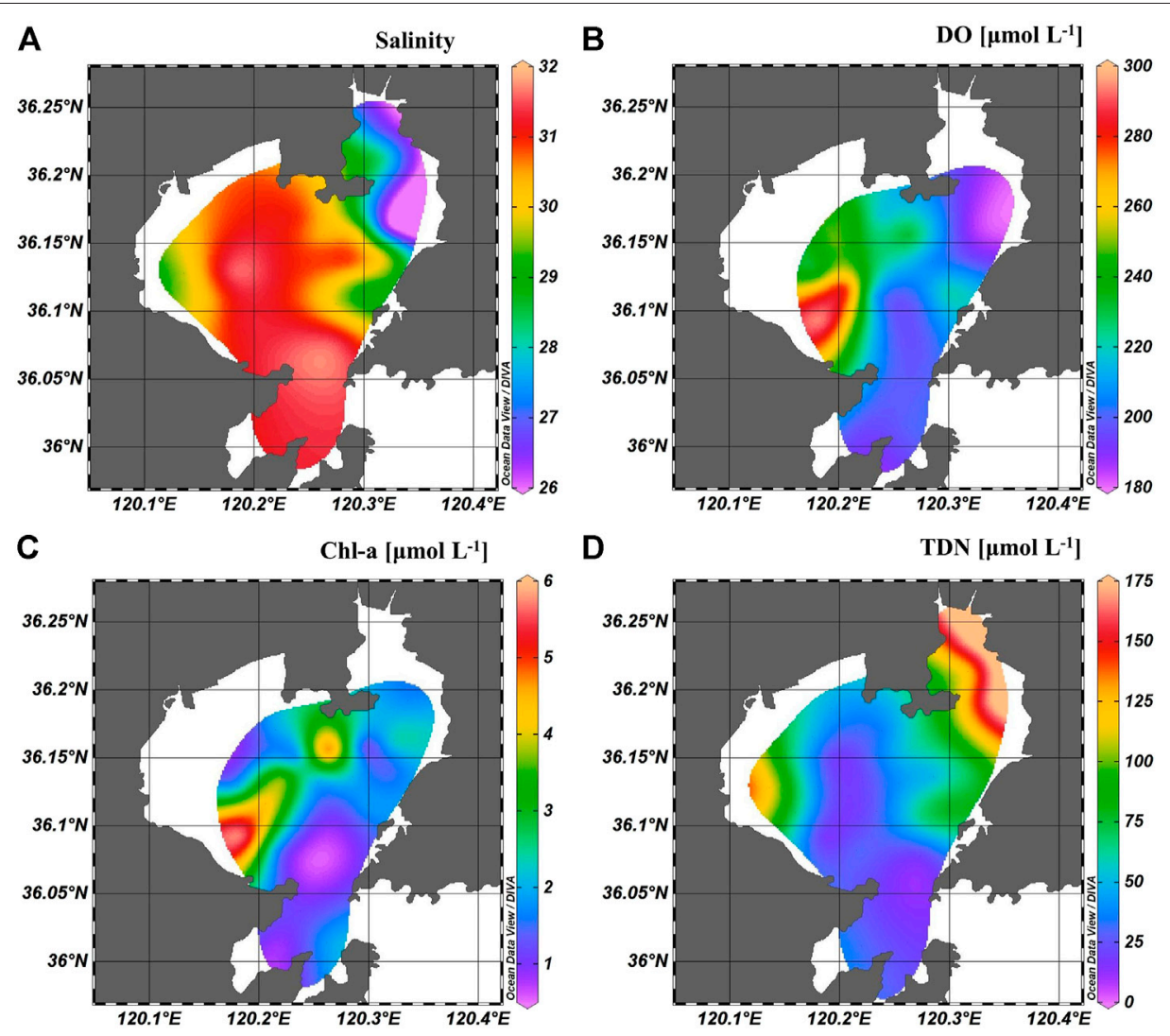

FIGURE 2|Surface distribution of salinity (A), DO (B), Chl-a (C), and TDN (D) in Jiaozhou Bay. This figure was made in Ocean Data View (ODV) using DIVA gridding.

(Huguet et al., 2009). The HIX increases with increasing humification degree, and could indicate the contribution of terrestrial organic matter (Zsolnay et al., 1999; Zhang et al., 2010).

\section{Parallel Factor Analysis}

A fluorescence dataset of 173 EEMs was analyzed by PARAFAC. The PARAFAC modeling was conducted using the DOMFluor toolbox on MATLAB R2020b (Mathworks, United States) according to the protocol described by Stedmon and Bro (2008). Before PARAFAC modeling, Raman normalization was conducted to enable comparison among different studies (Murphy et al., 2010), therefore the fluorescence intensity in this study was reported as Raman Unit (RU). In addition, to facilitate the modeling speed and to avoid the influence of scattering, the EEMs for PARAFAC modeling only covered the excitation range of $252-399 \mathrm{~nm}$ and the emission range of 


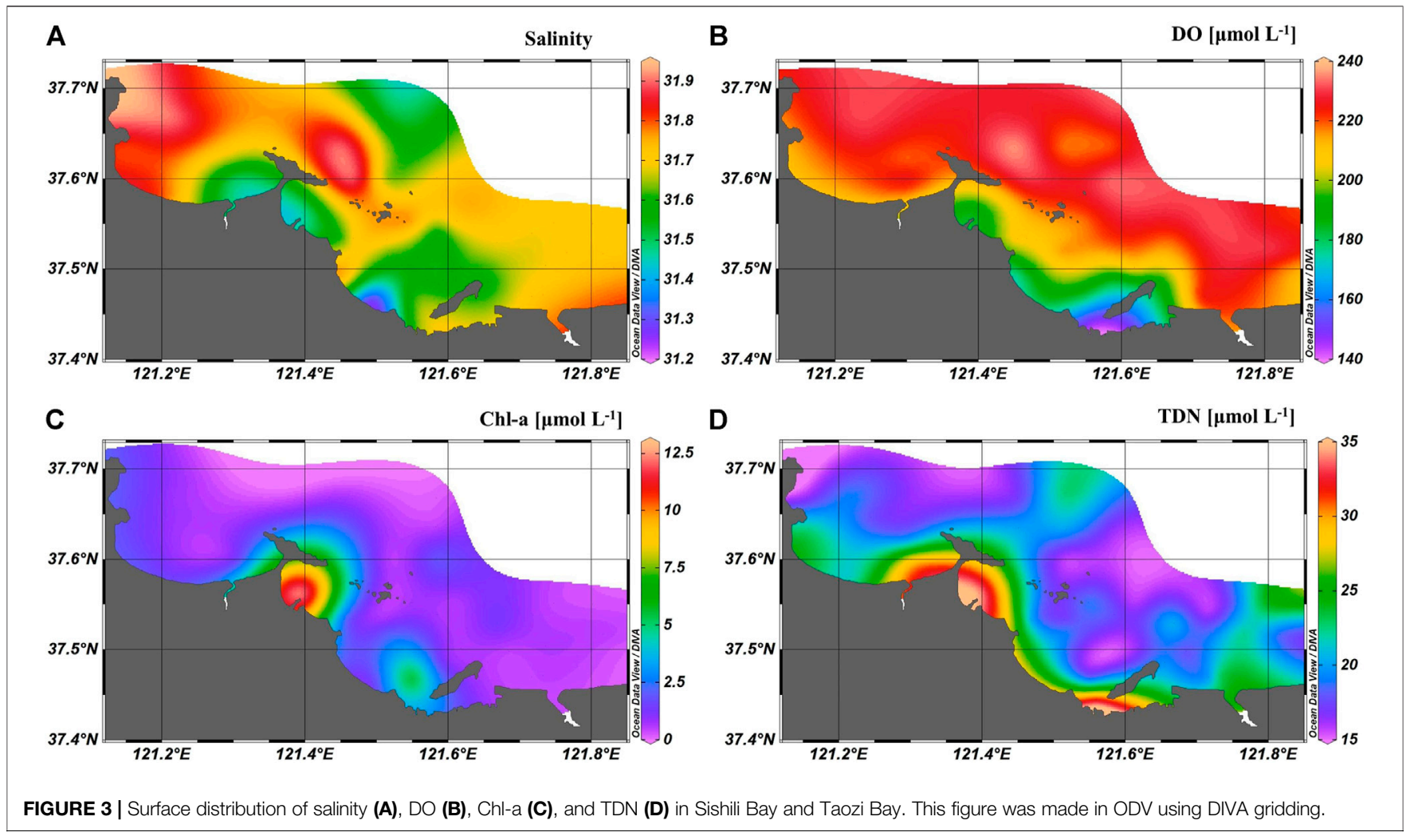

284-546 nm. A non-negativity constraint was applied, and a four-component model was confirmed based on split-half validation.

\section{RESULTS}

\section{Physicochemical Parameters}

The physicochemical parameters in the three bays are summarized in Table 1. The salinity ranged from 26.01 to 31.59 in Jiaozhou bay, while the salinity range in Sishili Bay and Taozi Bay was much narrower (Table 1). In Jiaozhou Bay, the lowest salinity was found in the northeastern area where the bay received discharges from urban rivers (Figure 2). In Sishili Bay (31.24-32.01) and Taozi Bay (31.49-31.95), the lowest salinity was also found near the river mouth along the coast (Figure 3). In contrast, the temperature in Jiaozhou Bay was relatively stable from surface to bottom, while the temperature showed a depth gradient in Sishili Bay and Taozi Bay. DO had a range of $168.8-293.7 \mu \mathrm{mol} \mathrm{L}^{-1}$ in Jiaozhou Bay, and $80.6-237.3 \mu \mathrm{mol}$ $\mathrm{L}^{-1}$ in Sishili Bay, and $164.4-231.3 \mu \mathrm{mol} \mathrm{L}^{-1}$ in Taozi Bay. In Jiaozhou Bay, low DO was found in the eastern part where the urban rivers flow into the bay, while high DO was found in the western area where there was high Chl-a (Figure 2). The lowest DO $\left(80.6 \mu \mathrm{mol} \mathrm{L}^{-1}\right)$ was found in the bottom water of Sishili Bay, indicating hypoxia occurred in this area. The highest Chl-a concentration $\left(15 \mu \mathrm{g} \mathrm{L}^{-1}\right)$ was recorded in one station near Zhifu Island in Sishili Bay. The TDN concentration ranged from $16.9-171.3 \mu \mathrm{mol} \mathrm{L} \mathrm{L}^{-1}$ with a mean $48.7 \pm 36.6 \mu \mathrm{mol} \mathrm{L}{ }^{-1}$ in Jiaozhou Bay, much higher than Sishili Bay $(21.4 \pm 5.26 \mu \mathrm{mol}$ $\left.\mathrm{L}^{-1}\right)$ and Taozi Bay $\left(22.0 \pm 4.22 \mu \mathrm{mol} \mathrm{L}^{-1}\right)$.

\section{Dissolved Organic Matter and Chromophoric Dissolved Organic Matter}

The DOC concentration had a range of $147.7-267.5 \mu \mathrm{mol} \mathrm{L}^{-1}$ in our study (Table 2), similar to the results reported in the same study area (Zhao et al., 2001; Zhang et al., 2009; Zhang et al., 2018). The SPE-DOM $\delta^{13} \mathrm{C}$ had a narrow range from $-24.8 \%$ o to $-22.9 \%$. There was higher DOC concentration and lower SPEDOM $\delta^{13} \mathrm{C}$ in bottom water than in surface water in Taozi Bay.

There was higher CDOM abundance $\left(a_{351}\right)$ in surface water than bottom water in Jiaozhou Bay, while there was no significant difference $(p>0.05)$ in CDOM abundance among different layers in Sishili Bay and Taozi Bay. There was lower $S_{275-295}$ in surface water than bottom water in Jiaozhou Bay and Taozi Bay, while there was higher $\mathrm{S}_{275-295}$ in surface water than bottom water in Sishili Bay.

\section{Fluorescent Dissolved Organic Matter}

Four fluorescent components were identified by PARAFAC, including one protein-like $(\mathrm{C} 1)$ and three humic-like $(\mathrm{C} 2, \mathrm{C} 3$, and C4) components (Figure 4). All four components were matched with the components identified in previous studies based on the OpenFluor database. C1, resembling traditionally defined peak B, has been reported as one tyrosine-like fluorophore ( $\mathrm{Li}$ et al., 2015). C2 has two excitation maxima at $<252$ and $309 \mathrm{~nm}$ with its emission maxima at $393 \mathrm{~nm}$. C2 


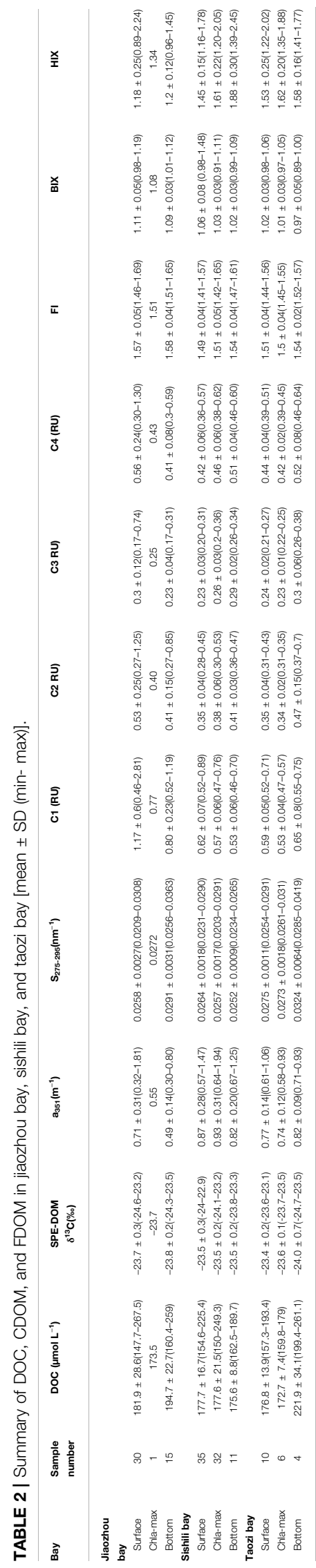

resembles traditionally defined peak $\mathrm{M}$, and has been regarded as microbially derived humic-like substances ( $\mathrm{Li}$ et al., 2016). C3 resembles a combination of traditionally defined peaks A and $\mathrm{C}$, and has been reported as terrestrially derived humic-like substances ( $\mathrm{Li}$ et al., 2015). C4 has its excitation maxima $<252 \mathrm{~nm}$ with its emission maxima at $453 \mathrm{~nm}$, resembling traditionally defined humic-like peak A (Coble, 2007). C4 has also been regarded as terrestrially derived humic-like substances.

The statistics of four identified PARAFAC components are shown in Table 2. There was a higher FDOM concentration (C1C4) in surface water than bottom water in Jiaozhou Bay. In contrast, there were higher concentrations of humic-like FDOM components in bottom water than surface water in Sishili Bay and Taozi Bay.

FI had similar ranges in three bays, with a range of 1.46-1.69 in Jiaozhou Bay, 1.34-1.61 in Sishili Bay and 1.44-1.57 in Taozi Bay. BIX had a range of $0.89-1.48$ in all samples from Jiaozhou Bay, Sishili Bay and Taozi Bay, suggesting a dominant autochthonous origin in the study area, which is supported by the low HIX $(0.89-2.24)$ in these three bays. There was higher HIX and lower BIX in bottom water than in surface water in Sishili Bay.

\section{DISCUSSION}

\section{Riverine Inputs of Dissolved Organic Matter}

In Jiaozhou Bay, high DOM abundance (DOC, $\mathrm{a}_{351}$, and four fluorescent components) was found in the northeastern and western area where rivers (Dagu River, Yang River, Moshui River, Loushan River, Licun River, and Haipo River) flow into the bay, suggesting riverine inputs of DOM (Zhang et al., 2009; Zhang and Yang, 2013; Hu et al., 2020) (Figure 5). Moreover, negative correlations between DOM abundance and salinity were identified (Table 3 ), suggesting that conservative mixing between freshwater and seawater controlled the distribution of DOM in Jiaozhou Bay (Zhang and Yang, 2013). In addition, the correlation coefficients varied among different fluorescent components ( $\mathrm{C} 1$ to $\mathrm{C} 4$; Table 3), suggesting that the degree of the influence of mixing on DOM varied among different components.

In Sishili Bay and Taozi Bay, high DOM abundance was found in the nearshore area, especially in the area near the mouth of Jia River and Xin'an River, indicating a contribution of riverine input (Figure 6). However, the riverine input had a limited influence on DOM abundance in the whole bay area, which could be corroborated by the narrow salinity ranges observed in these two bays (Table 1), consistent with a previous study (Zhang et al., 2018). The limited influence of riverine discharge on DOM abundance could be possibly explained by the characteristics of the inflowing rivers and the bays. First, the inflowing rivers are relatively small and have low flow rates. Moreover, these two bays are relatively open, allowing an exchange of water between the inner and outer bay (Dong et al., 2019).

Riverine inputs had their signatures on the optical properties and stable isotopic properties of DOM in Jiaozhou Bay. Lower 

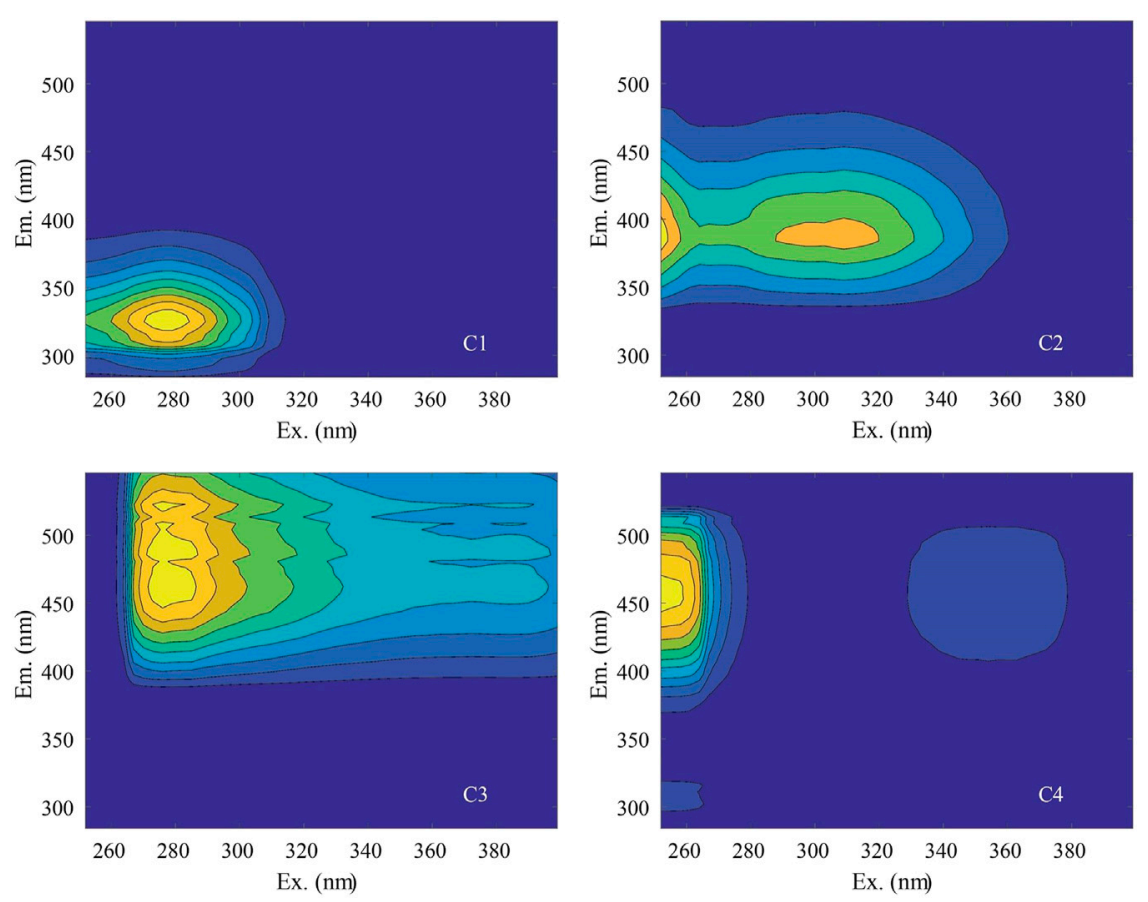

FIGURE 4 | Fluorescence spectra of four PARAFAC components identified in this study.

$\mathrm{S}_{275-295}$ values were found in the northeastern and northwestern part of Jiaozhou Bay (Figure 7), which could be attributed to the input of terrestrial-derived DOM from inflowing rivers (Helms et al., 2008). Higher FI and BIX values were found in the eastern part of Jiaozhou Bay (Figure 7), indicating a stronger input of microbial-derived source or an autochthonous source (Huguet et al., 2009; Cory et al., 2010). Lower HIX was found in the eastern part of Jiaozhou Bay (Figure 7), suggesting a lower humification degree of DOM, corroborating with higher FI and BIX. In contrast, relatively higher HIX was found in the western part of Jiaozhou bay, where Dagu River and Yang River flow into the bay (Figure 7). On the western coast of Jiaozhou Bay, the land cover is dominated by agricultural land, while on the eastern coast, the land cover is dominated by urban areas (Ke et al., 2020). Previous studies have shown that rivers draining agricultural land had a higher concentration of humic-like components and higher HIX, while rivers flowing through the urban area had higher concentrations of protein-like and microbial-derived humic-like components, and higher FI and BIX values due to domestic wastewater input (Shang et al., 2018; Chen et al., 2019). In addition to optical properties, the values of SPE-DOM $\delta^{13} \mathrm{C}$ indicate a mixture of terrestrial- and marine phytoplanktonderived DOM (Cawley et al., 2012), and they differed in these two areas of Jiaozhou Bay. Lower SPE-DOM $\delta^{13} \mathrm{C}$ values were found in the northeastern part of the bay, which could be attributed to the input of ${ }^{13} \mathrm{C}$-depleted terrestrial organic matter (e.g., C3 plants or freshwater phytoplankton) through riverine discharge. This pattern is similar to the distribution of particulate organic matter (POM) $\delta^{13} \mathrm{C}$ observed during summer in the same area (Ke et al., 2020).
In addition to land cover, sewage discharge, aquaculture and dumping also had their effect on DOM. DOC and three humic components $(\mathrm{C} 2, \mathrm{C} 3$, and $\mathrm{C} 4)$ exerted high concentrations in the southeast side of Zhifu Island (Figure 6), which could be attributed to the discharge of domestic and industrial sewage (Wang et al., 2012). Meanwhile, in southeast stations of Sishili Bay, high concentrations of DOC, C1 and C2 could be possibly attributed to aquaculture activities, consistent with previous studies (Zhao et al., 2001; Li et al., 2018). Moreover, high CDOM $\left(\mathrm{a}_{351}\right)$ abundance was found in the northern part of Sishili Bay, which could be attributed to marine dumping activities (Wang et al., 2012).

\section{Multiple Mechanisms Controlling the Vertical Distribution of Dissolved Organic Matter}

In estuarine and coastal regions, DOM concentration is generally dominated by the mixing between freshwater and seawater. Therefore, there is often higher DOM in low salinity surface water than that in bottom water due to freshwater input ( $\mathrm{Li}$ et al., 2015). As expected, high DOM abundance (DOC, C1-C4) was observed in surface water in most stations of Jiaozhou Bay (Table 2; Figure 8). Considering similar salinity observed in surface and bottom water in Taozi Bay and Sishili Bay, DOM concentration in surface and that in bottom water should also be similar. However, there was a higher average DOM abundance in bottom water than in surface water in Sishili Bay and Taozi Bay (Table 2; Figure 8). Higher DOC and FDOM concentrations were found in bottom water than that in surface water in Taozi 


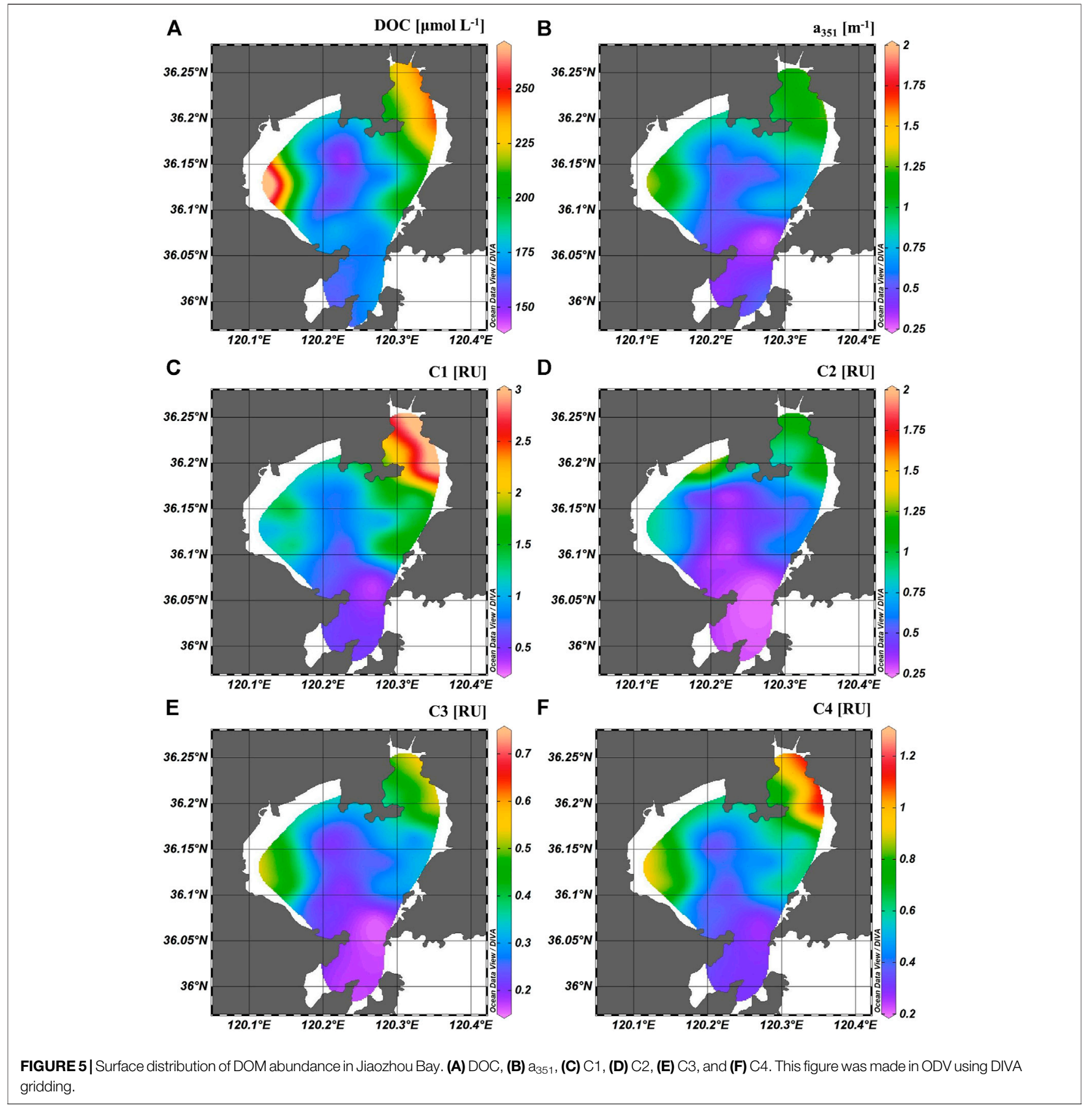

TABLE 3 | Summary of correlations between salinity and DOM abundance in Jiaozhou Bay.

\begin{tabular}{lcc} 
DOM abundance & $\mathbf{R}$ & $\mathbf{P}$ \\
\hline DOC & -0.58 & $<0.001$ \\
$\mathrm{~A}_{351}$ & -0.71 & $<0.001$ \\
C1 & -0.95 & $<0.001$ \\
C2 & -0.80 & $<0.001$ \\
C3 & -0.69 & $<0.001$ \\
C4 & -0.78 & $<0.001$
\end{tabular}

Bay. In Sishili Bay, three humic-like components were also found to be higher in bottom water than that in surface water. Theoretically, two possibilities could cause higher DOM abundance in bottom water than in surface water. First, DOM in surface water decreased due to a series of removal processes (e.g., photodegradation and microbial degradation). Second, DOM in bottom water increased due to additional inputs (e.g., sediment resuspension and subsequent release) (Li et al., 2015). To check which is the main reason behind the vertical 


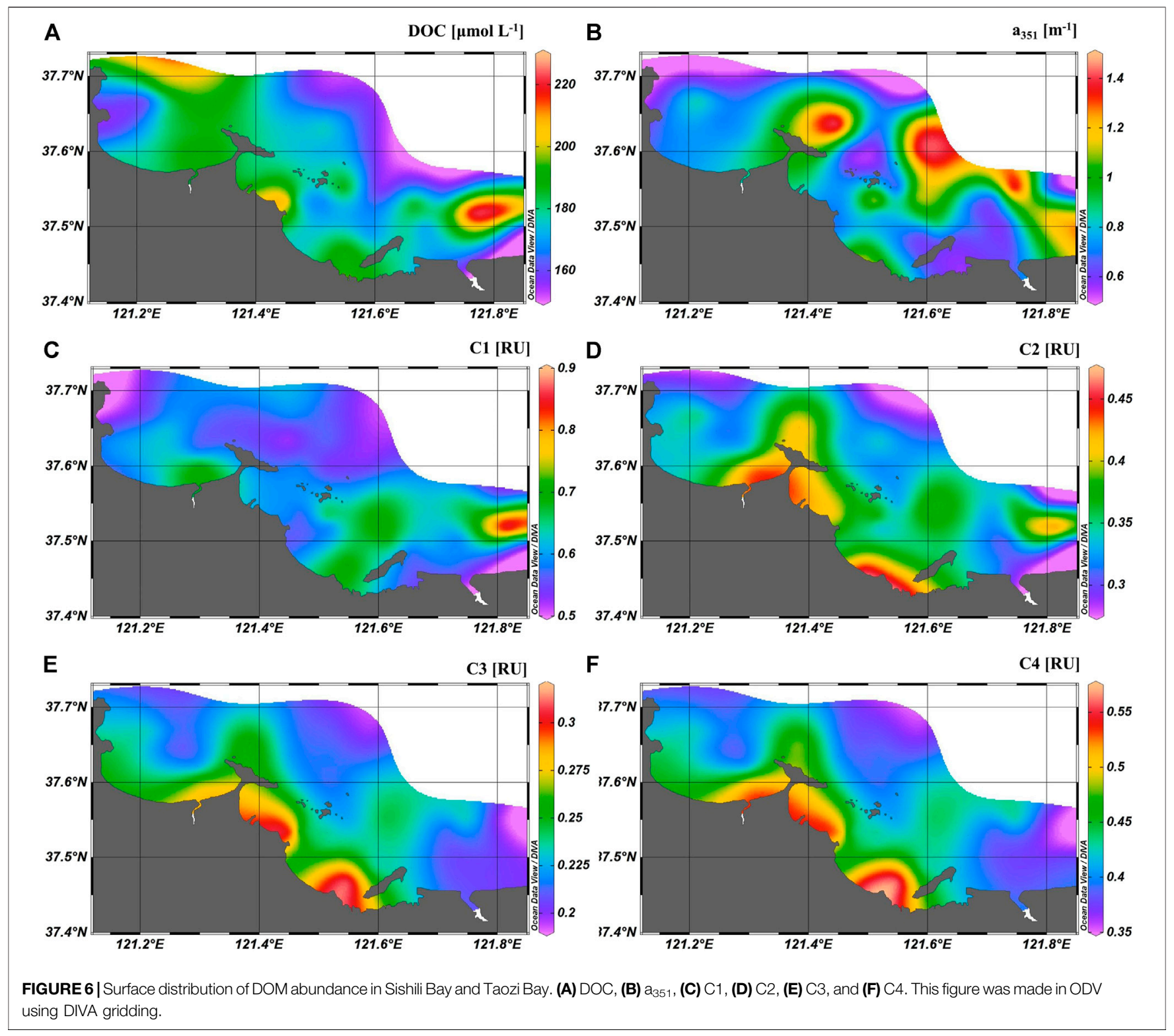

distribution of DOM in these two bays, a cross-bay comparison has been made for all three bays of this study. A similar concentration of humic-like components (C2-C4) was found in surface water samples with similar salinity in all three bays, while higher humiclike components were found in bottom water samples of Sishili Bay and Taozi Bay than that in bottom water samples of Jiaozhou Bay (Figure 9). These results suggest that the second one (additional inputs at bottom layer) should be the main underlying reason.

Previous studies suggested that sediment resuspension could be an important source for DOM in estuarine and coastal regions (Li et al., 2015). Due to shallow depth, sediment resuspension triggered by wind or tidal forces frequently occurs in estuarine and coastal regions, driving the release of DOM from sediment pore water into the overlying water, and thus resulting in high DOM concentration in bottom water. The DOM abundance, especially protein-like components, was found to be elevated in the Yangtze estuary due to sediment resuspension (Li et al., 2015). However, a previous study showed that the tidal current inside Sishili Bay is weak (Li et al., 2013). Besides, the wind is not strong in summer, which could be supported by the depth gradient of temperature in Sishili Bay and Taozi Bay. Moreover, scallops are cultivated in suspended lantern nets, not disturbing sediments. Therefore, wind or tidal forces or aquaculture could not be able to drive sediment resuspension, and thus sediment resuspension and subsequent release of DOM should not be the main mechanism for high DOM concentration in bottom water in this study.

Aquaculture activities could be a possible reason behind high DOM abundance in bottom water in Sishili Bay and Taozi Bay. High DOC concentration has been reported in the aquaculture area of Sishili Bay (Zhao et al., 2001). Previous studies have found high DOC concentration at bottom water of aquaculture area and 


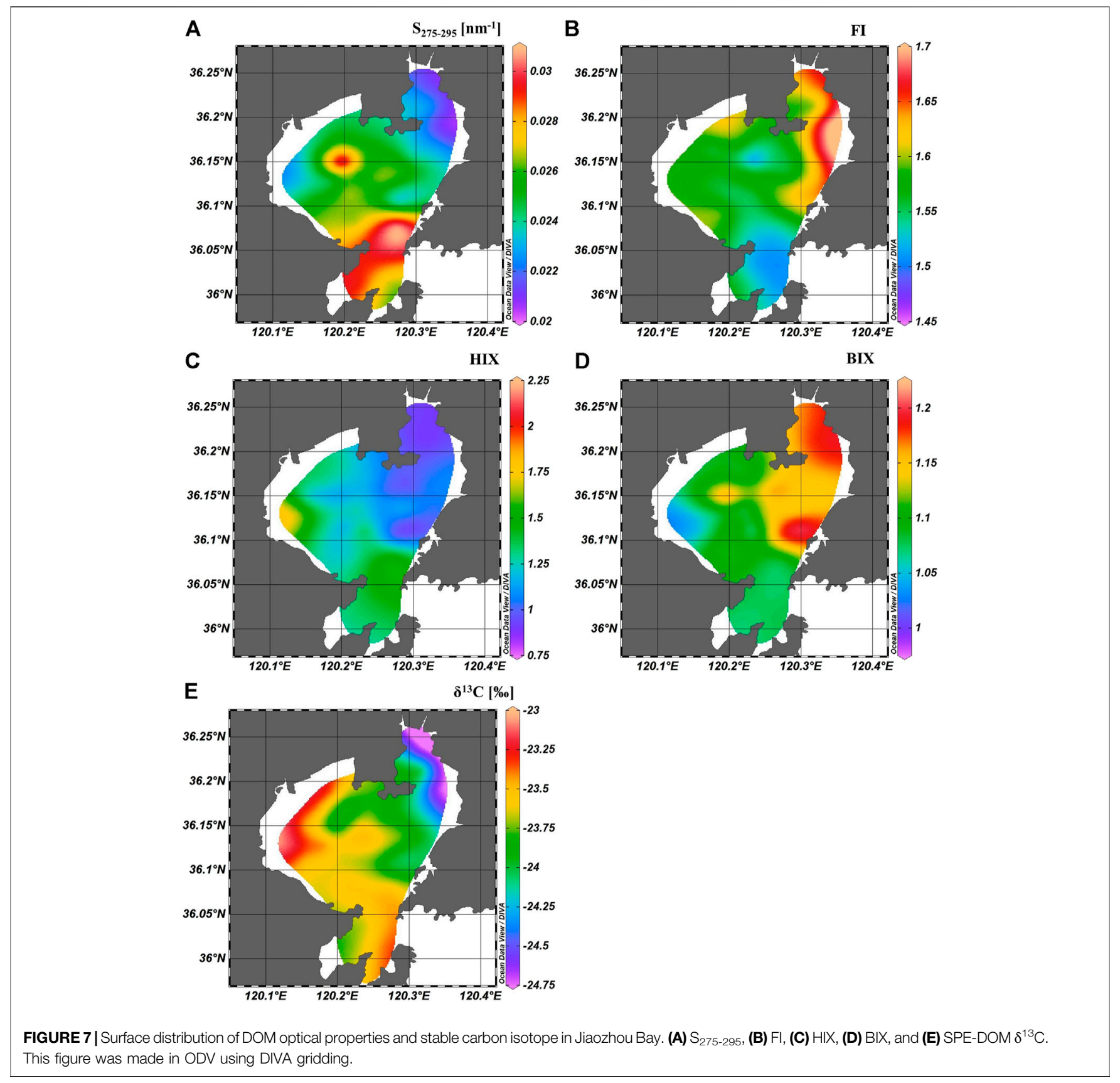

attributed it to accumulation due to long-term aquaculture activities (Mahmood et al., 2017; Li et al., 2018). Besides, elevated humic-like components have also been found in bottom water in areas of kelp culture (Li et al., 2018), similar to the distribution observed in Sishili Bay and Taozi Bay. However, it should be noted that the effects of aquaculture on DOM depend on the species of culture and the growth phase (Mahmood et al., 2017). In this study, there is no significant difference between surface DOC and bottom DOC in Sishili Bay. In Sishili Bay and Taozi Bay, scallops are the main cultural species. A previous study has shown that scallops could either increase or decrease DOC concentration (Mahmood et al., 2017). The increase of DOC was mostly attributed to DOC excretion, while the decrease was mostly caused by DOC uptake through filter-feeding (Mahmood et al., 2017).

Besides sediment resuspension and aquaculture activities, biological production could also be another important source of DOM at the bottom layer. Humic-like components could be produced in deep water through biological production based on a significant correlation $(p<0.001)$ between humic-like components and AOU (Yamashita and Tanoue, 2008). In this 


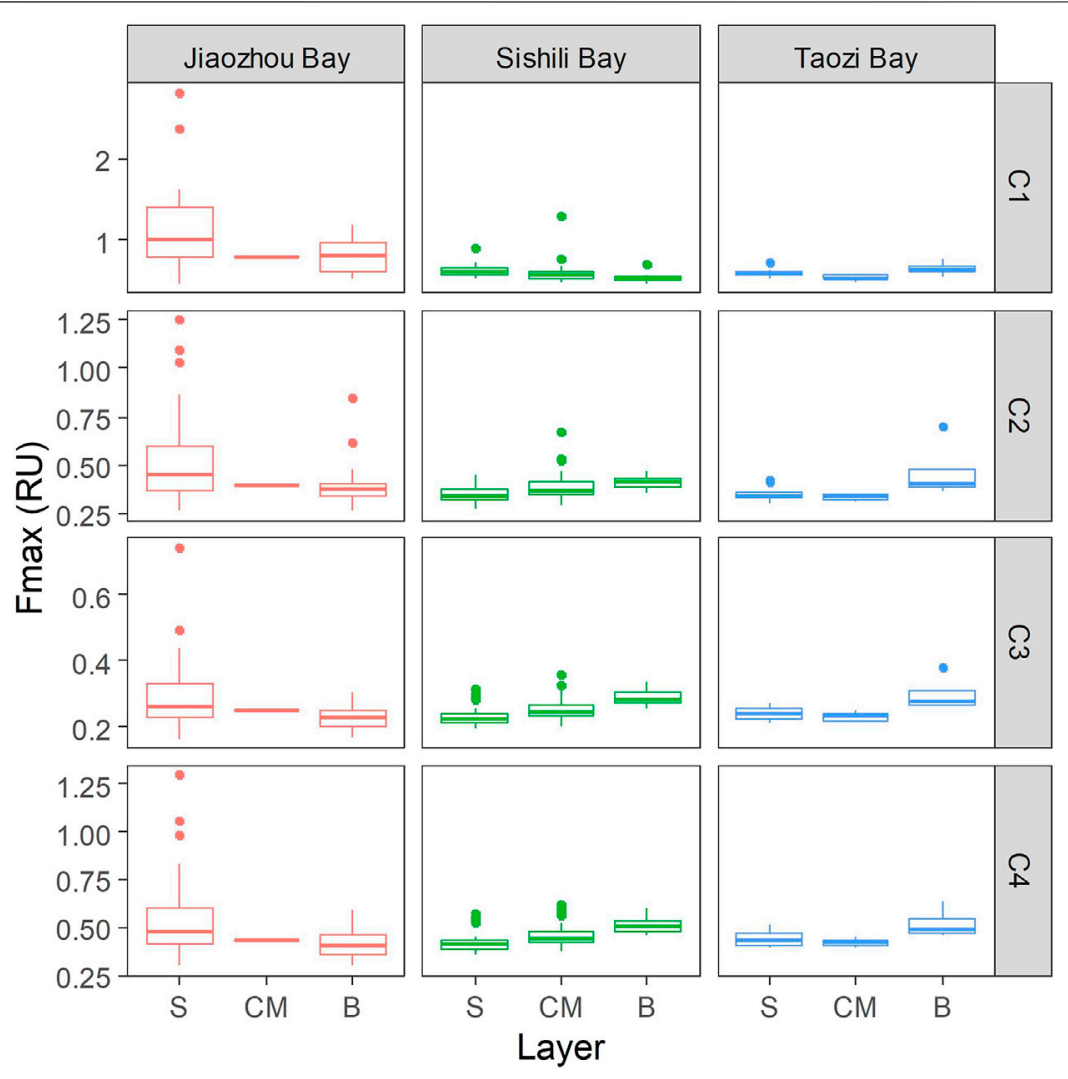

FIGURE 8 | Boxplots of four PARAFAC components in different layers (S, Surface; CM, Chl-a Max; B, Bottom) of three bays (Jiaozhou Bay, Sishili Bay, and Taozi Bay).

study, significant correlations $(p<0.05)$ between $\mathrm{AOU}$ and humic-like components (C3 and $\mathrm{C} 4$ in Jiaozhou Bay, $\mathrm{C} 2-\mathrm{C} 4$ in Sishili Bay) are also found in the bottom water of Jiaozhou Bay and Sishili Bay (Table 4), indicating that biological production is an important source of DOM and could be the main reason behind the vertical distribution of DOM in our study area. It should be noted that there are only three bottom samples available in Taozi Bay, which could be the reason that there is no correlation found between humic-like components and AOU in Taozi Bay.

Although aquaculture and biological production could be the main reasons behind high DOM abundance at bottom water in Taozi Bay and Sishili Bay, photodegradation/ photobleaching also has its effect on the distribution of DOM. There are some stations with higher humic-like components (C2-C4) in bottom water than in surface water in Jiaozhou Bay, although there is higher DOM abundance in surface water than in bottom water in most stations of Jiaozhou Bay. These results are consistent with that humic-like components are more susceptible to photodegradation (Lønborg et al., 2015; Yang et al., 2020). Moreover, there are higher $\mathrm{S}_{275-295}$ in surface water than that in bottom water in most stations of Sishili Bay, indicating photobleaching is an important factor influencing surface DOM.

\section{Primary and Microbial Production}

In Sishili Bay, positive correlations have been identified between Chl-a and three humic-like components in surface water (Table 4), suggesting that primary production could be an important source of DOM. Correlation between Chl-a and DOM abundance (DOC) has also been reported in the surface layer of Jiaozhou Bay (Zhang and Yang, 2013), partly corroborating our results. Also, Chl-a was found to be positively related to TDN, indicating TDN was a major controlling factor of primary production in this region (Wetz et al., 2017). Moreover, correlations have been found between AOU and three humic-like components in surface water. These correlations have been found in the deep ocean, and have been attributed to biological oxidation of organic matter and subsequent production of humic-like organic matter (Yamashita and Tanoue, 2008). In most cases, there was no correlation between AOU and humiclike components observed in the surface water due to the air-sea gas exchange. The correlation between AOU and humic-like components observed in the surface water of Sishili Bay corroborated that the tidal current within the bay is weak so that the oxygen consumed by microbial activities cannot be immediately replenished through the air-sea exchange. Therefore, we could conclude that the TDN 


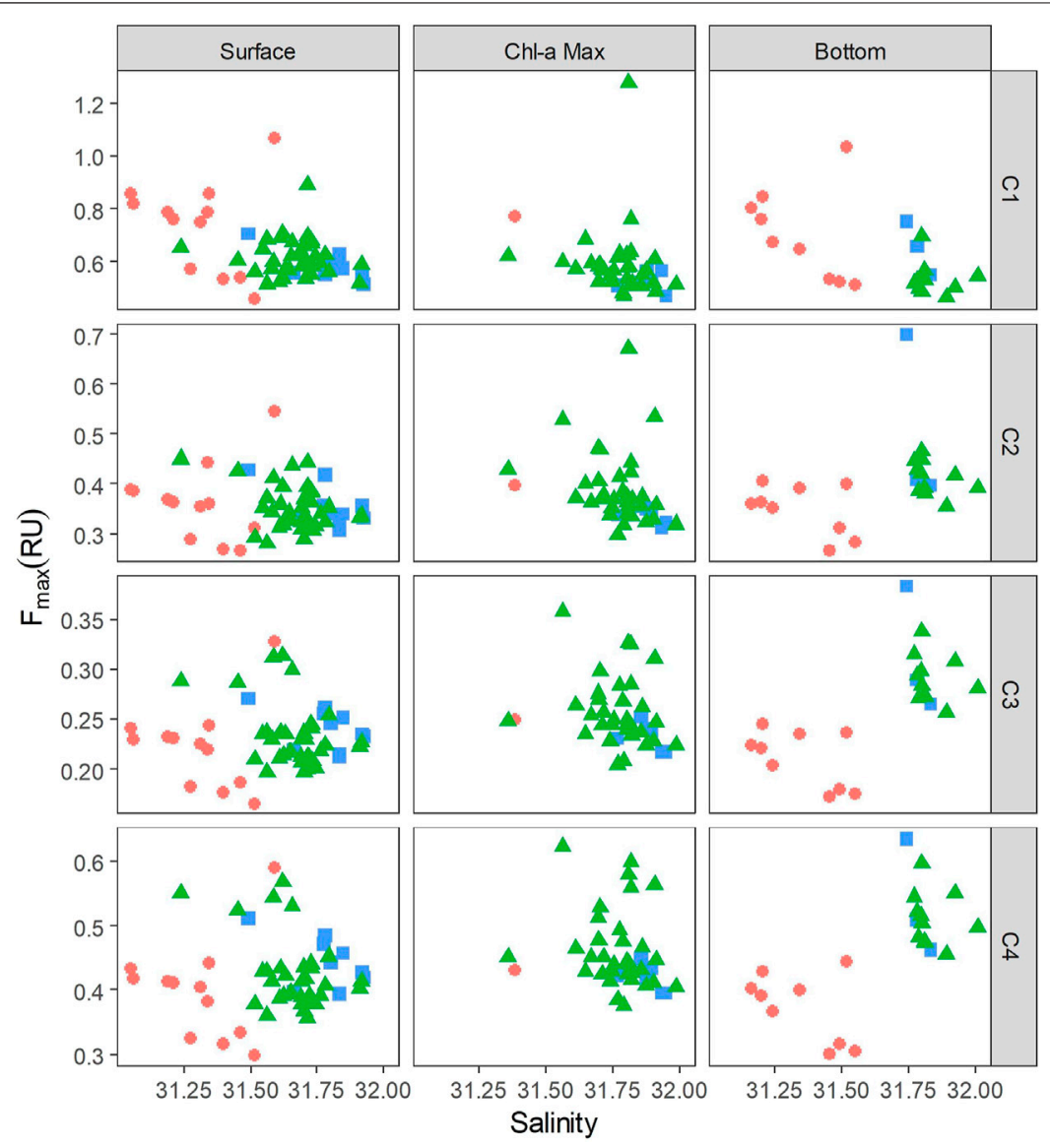

FIGURE 9 | Four PARAFAC components in samples with salinity in the range of 31-32 in different layers of three bays. Samples from Jiaozhou Bay are marked by red circles), samples from Sishili Bay are marked by green triangles, and samples from Taozi Bay are marked by blue squares.

TABLE 4 | Summary of correlations between different parameters.

\begin{tabular}{lccccc} 
Parameter A & Parameter B & $\mathbf{R}$ & $\mathbf{P}$ & Area & Layer \\
\hline AOU & C1 & 0.69 & 0.019 & Jiaozhou bay & Bottom \\
AOU & C2 & 0.48 & 0.134 & Jiaozhou bay & Bottom \\
AOU & C3 & 0.66 & 0.028 & Jiaozhou bay & Bottom \\
AOU & C4 & 0.75 & 0.008 & Jiaozhou bay & Bottom \\
AOU & C2 & 0.67 & 0.024 & Sishili bay & Bottom \\
AOU & C3 & 0.81 & 0.002 & Sishili bay & Bottom \\
AOU & C4 & 0.77 & 0.006 & Sishili bay & Bottom \\
Chl-a & C2 & 0.44 & 0.008 & Sishili bay & Surface \\
Chl-a & C3 & 0.61 & $<0.001$ & Sishili bay & Surface \\
Chl-a & C4 & 0.62 & $<0.001$ & Sishili bay & Surface \\
Chl-a & TDN & 0.59 & $<0.001$ & Sishili bay & Surface \\
TDN & C2 & 0.38 & 0.025 & Sishili bay & Surface \\
TDN & C3 & 0.47 & 0.004 & Sishili bay & Surface \\
TDN & C4 & 0.47 & 0.007 & Sishili bay & Surface \\
AOU & C2 & 0.51 & 0.001 & Sishili bay & Surface \\
AOU & C3 & 0.70 & $<0.001$ & Sishili bay & Surface \\
AOU & C4 & 0.71 & $<0.001$ & Sishili bay & Surface \\
\hline
\end{tabular}

concentration could affect, to some extent, the concentration of humic-like components in surface water in Sishili Bay.

\section{CONCLUSION}

Multiple sources and processes regulate DOM in coastal bays in this study. Riverine inputs are one of the most important DOM sources in coastal bays, and the effects vary with the discharges and watershed characteristics (agricultural and urban activities) of inflowing rivers, and also the geomorphology of the bays. There is a higher DOM abundance, especially humic-like FDOM components, in the bottom water of Sishili Bay and Taozi Bay, which could be attributed to aquaculture activities and biological production at the bottom layer. Besides, significant correlations have been found between physicochemical parameters (TDN, Chl-a, and AOU) and DOM abundance (humic-like components), indicating eutrophication and subsequently enhanced primary and microbial production are important factors controlling DOM abundance and distribution in coastal bays. Moreover, photodegradation/photobleaching, dumping and sewage discharge had their effects on DOM in this study. This study demonstrates that DOM in coastal bays is strongly influenced by anthropogenic activities and that spectroscopic and isotopic methods are useful for elucidating the source 
and mechanism regulating DOM abundance and distribution in coastal bays.

\section{DATA AVAILABILITY STATEMENT}

All datasets generated for this study are included in the article, further inquiries can be directed to the corresponding author.

\section{AUTHOR CONTRIBUTIONS}

DH contributed to the design of the study. All authors performed the experiment. PL analyzed the data. PL and $\mathrm{DH}$ prepared the manuscript. All authors contributed to the revision.

\section{REFERENCES}

Arar, E. J., and Collins, G. B. (1997). Method 445.0: In Vitro Determination of Chlorophyll $a$ and Pheophytin $a$ in marine and Freshwater Algae by Fluorescence. Washington, DC: United States Environmental Protection Agency, Office of Research and Development, National Exposure Research Laboratory.

Asmala, E., Haraguchi, L., Markager, S., Massicotte, P., Riemann, B., Staehr, P. A., et al. (2018). Eutrophication Leads to Accumulation of Recalcitrant Autochthonous Organic Matter in Coastal Environment. Glob. Biogeochem. Cycles 32, 1673-1687. doi:10.1029/2017gb005848

Bianchi, T. S. (2011). The Role of Terrestrially Derived Organic Carbon in the Coastal Ocean: A Changing Paradigm and the Priming Effect. Proc. Natl. Acad. Sci. 108, 19473-19481. doi:10.1073/pnas.1017982108

Cai, W.-J. (2011). Estuarine and Coastal Ocean Carbon Paradox: CO2Sinks or Sites of Terrestrial Carbon Incineration? Annu. Rev. Mar. Sci. 3, 123-145. doi:10.1146/annurev-marine-120709-142723

Cai, W.-J., Hu, X., Huang, W.-J., Murrell, M. C., Lehrter, J. C., Lohrenz, S. E., et al. (2011). Acidification of Subsurface Coastal Waters Enhanced by Eutrophication. Nat. Geosci. 4, 766-770. doi:10.1038/ngeo1297

Casas-Ruiz, J. P., Catalán, N., Gómez-Gener, L., Von Schiller, D., Obrador, B., Kothawala, D. N., et al. (2017). A Tale of Pipes and Reactors: Controls on the InStream Dynamics of Dissolved Organic Matter in Rivers. Limnol. Oceanogr. 62, S85-S94. doi:10.1002/lno.10471

Cawley, K. M., Ding, Y., Fourqurean, J., and Jaffé, R. (2012). Characterising the Sources and Fate of Dissolved Organic Matter in Shark Bay, Australia: a Preliminary Study Using Optical Properties and Stable Carbon Isotopes. Mar. Freshw. Res. 63, 1098-1107. doi:10.1071/mf12028

Chen, S., Lu, Y., Dash, P., Das, P., Li, J., Capps, K., et al. (2019). Hurricane Pulses: Small Watershed Exports of Dissolved Nutrients and Organic Matter during Large Storms in the Southeastern USA. Sci. Total Environ. 689, 232-244. doi:10.1016/j.scitotenv.2019.06.351

Coble, P. G. (2007). Marine Optical Biogeochemistry: The Chemistry of Ocean Color. Chem. Rev. 107, 402-418. doi:10.1021/cr050350+

Coble, P. G., Spencer, R. G., Baker, A., and Reynolds, D. M. (2014). “Aquatic Organic Matter Fluorescence," in Aquatic Organic Matter Fluorescence Editors P. Coble, J. Lead, A. Baker, D. Reynolds, and R. G. M. Spencer (Cambridge: Cambridge University Press), 75-122

Cory, R. M., and Mcknight, D. M. (2005). Fluorescence Spectroscopy Reveals Ubiquitous Presence of Oxidized and Reduced Quinones in Dissolved Organic Matter. Environ. Sci. Technol. 39, 8142-8149. doi:10.1021/ es0506962

Cory, R. M., Miller, M. P., Mcknight, D. M., Guerard, J. J., and Miller, P. L. (2010). Effect of Instrument-specific Response on the Analysis of Fulvic Acid Fluorescence Spectra. Limnol. Oceanogr. Methods 8, 67-78. doi:10.4319/ lom.2010.8.67

\section{FUNDING}

This study is supported by National Natural Science Foundation of China (grant No. 41973070), NSFC Shandong joint fund (grant No. U1706219), GuangDong Basic and Applied Basic Research Foundation (grant No. 2020A1515110194), and innovation Group Project of Southern Marine Science and Engineering Guangdong Laboratory (Zhuhai) (grant No. 311019006/311020006).

\section{ACKNOWLEDGMENTS}

We thank the cruise members for their help during the sampling.

Dittmar, T., Koch, B., Hertkorn, N., and Kattner, G. (2008). A Simple and Efficient Method for the Solid-phase Extraction of Dissolved Organic Matter (SPEDOM) from Seawater. Limnol. Oceanogr. Methods 6, 230-235. doi:10.4319/ lom.2008.6.230

Dong, Z., Liu, D., Wang, Y., and Di, B. (2019). Temporal and Spatial Variations of Coastal Water Quality in Sishili Bay, Northern Yellow Sea of China. Aquat. Ecosystem Health Manag. 22, 30-39. doi:10.1080/14634988.2018.1525264

Fichot, C. G., and Benner, R. (2012). The Spectral Slope Coefficient of Chromophoric Dissolved Organic Matter (S 275-295) as a Tracer of Terrigenous Dissolved Organic Carbon in River-Influenced Ocean Margins. Limnol. Oceanogr. 57, 1453-1466. doi:10.4319/lo.2012.57.5.1453

Guéguen, C., Mokhtar, M., Perroud, A., Mccullough, G., and Papakyriakou, T. (2016). Mixing and Photoreactivity of Dissolved Organic Matter in the Nelson/ Hayes Estuarine System (Hudson Bay, Canada). J. Mar. Syst. 161, 42-48. doi:10.1016/j.jmarsys.2016.05.005

Hansell, D. A., and Carlson, C. A. (2015). Biogeochemistry of Marine Dissolved Organic Matter. Amsterdam, Boston. Academic Press.

He, C., Pan, Q., Li, P., Xie, W., He, D., Zhang, C., et al. (2020). Molecular Composition and Spatial Distribution of Dissolved Organic Matter (DOM) in the Pearl River Estuary, China. Environ. Chem. 17, 240-251. doi:10.1071/ en 19051

Helms, J. R., Stubbins, A., Ritchie, J. D., Minor, E. C., Kieber, D. J., and Mopper, K. (2008). Absorption Spectral Slopes and Slope Ratios as Indicators of Molecular Weight, Source, and Photobleaching of Chromophoric Dissolved Organic Matter. Limnol. Oceanogr. 53, 955-969. doi:10.4319/lo.2008.53.3.0955

Hu, J., Zou, L., Wang, J., Ren, Q., Xia, B., and Yu, G. (2020). Factors Regulating the Compositions and Distributions of Dissolved Organic Matter in the Estuaries of Jiaozhou Bay in North China. Oceanologia 62, 101-110. doi:10.1016/ j.oceano.2019.09.002

Huguet, A., Vacher, L., Relexans, S., Saubusse, S., Froidefond, J. M., and Parlanti, E. (2009). Properties of Fluorescent Dissolved Organic Matter in the Gironde Estuary. Org. Geochem. 40, 706-719. doi:10.1016/j.orggeochem.2009.03.002

Jennerjahn, T. C., and Ittekkot, V. (2002). Relevance of Mangroves for the Production and Deposition of Organic Matter along Tropical continental Margins. Naturwissenschaften 89, 23-30. doi:10.1007/s00114-001-0283-x

Ke, Z., Chen, D., Liu, J., and Tan, Y. (2020). The Effects of Anthropogenic Nutrient Inputs on Stable Carbon and Nitrogen Isotopes in Suspended Particulate Organic Matter in Jiaozhou Bay, China. Continental Shelf Res. 208, 104244. doi:10.1016/j.csr.2020.104244

Li, B., Keesing, J. K., Liu, D., Han, Q., Wang, Y., Dong, Z., et al. (2013). Anthropogenic Impacts on Hyperbenthos in the Coastal Waters of Sishili Bay, Yellow Sea. Chin. J. Ocean. Limnol. 31, 1257-1267. doi:10.1007/s00343013-2173-4

Li, H., Zhang, Y., Liang, Y., Chen, J., Zhu, Y., Zhao, Y., et al. (2018). Impacts of Maricultural Activities on Characteristics of Dissolved Organic Carbon and Nutrients in a Typical Raft-Culture Area of the Yellow Sea, North China. Mar. Pollut. Bull. 137, 456-464. doi:10.1016/j.marpolbul.2018.10.048 
Li, P., Chen, L., Zhang, W., and Huang, Q. (2015). Spatiotemporal Distribution, Sources, and Photobleaching Imprint of Dissolved Organic Matter in the Yangtze Estuary and its Adjacent Sea Using Fluorescence and Parallel Factor Analysis. Plos One 10. doi:10.1371/journal.pone.0130852

Li, P., and Hur, J. (2017). Utilization of UV-Vis Spectroscopy and Related Data Analyses for Dissolved Organic Matter (DOM) Studies: A Review. Crit. Rev. Environ. Sci. Tech. 47, 131-154. doi:10.1080/10643389.2017.1309186

Li, P., Lee, S. H., Lee, S. H., Lee, J.-B., Lee, Y. K., Shin, H.-S., et al. (2016). Seasonal and Storm-Driven Changes in Chemical Composition of Dissolved Organic Matter: a Case Study of a Reservoir and its Forested Tributaries. Environ. Sci. Pollut. Res. 23, 24834-24845. doi:10.1007/s11356-016-7720-z

Liang, Y., Cheng, X., Zhu, H., Shutes, B., Yan, B., Zhou, Q., et al. (2018). Historical Evolution of Mariculture in China during Past 40 Years and its Impacts on Eco-Environment. Chin. Geogr. Sci. 28, 363-373. doi:10.1007/ s11769-018-0940-z

Liu, X., Dunne, J. P., Stock, C. A., Harrison, M. J., Adcroft, A., and Resplandy, L. (2019). Simulating Water Residence Time in the Coastal Ocean: A Global Perspective. Geophys. Res. Lett. 46, 13910-13919. doi:10.1029/ $2019 \mathrm{gl} 1085097$

Lønborg, C., Carreira, C., Jickells, T., and Álvarez-Salgado, X. A. (2020). Impacts of Global Change on Ocean Dissolved Organic Carbon (DOC) Cycling. Front. Mar. Sci. 7, 466. doi:10.3389/fmars.2020.00466

Lønborg, C., Yokokawa, T., Herndl, G. J., and Antón Álvarez-Salgado, X. (2015). Production and Degradation of Fluorescent Dissolved Organic Matter in Surface Waters of the Eastern north Atlantic Ocean. Deep Sea Res. Oceanographic Res. Pap. 96, 28-37. doi:10.1016/j.dsr.2014.11.001

Mahmood, T., Fang, J., Jiang, Z., Ying, W., and Zhang, J. (2017). Seasonal Distribution, Sources and Sink of Dissolved Organic Carbon in Integrated Aquaculture System in Coastal Waters. Aquacult. Int. 25, 71-85. doi:10.1007/ s10499-016-0014-0

Mcknight, D. M., Boyer, E. W., Westerhoff, P. K., Doran, P. T., Kulbe, T., and Andersen, D. T. (2001). Spectrofluorometric Characterization of Dissolved Organic Matter for Indication of Precursor Organic Material and Aromaticity. Limnol. Oceanogr. 46, 38-48. doi:10.4319/lo.2001.46.1.0038

Moran, M. A., Kujawinski, E. B., Stubbins, A., Fatland, R., Aluwihare, L. I., Buchan, A., et al. (2016). Deciphering Ocean Carbon in a Changing World. Proc. Natl. Acad. Sci. 113, 3143. doi:10.1073/pnas.1514645113

Murphy, K. R., Butler, K. D., Spencer, R. G. M., Stedmon, C. A., Boehme, J. R., and Aiken, G. R. (2010). Measurement of Dissolved Organic Matter Fluorescence in Aquatic Environments: an Interlaboratory Comparison. Environ. Sci. Technol. 44, 9405-9412. doi:10.1021/es102362t

Raymond, P. A., and Bauer, J. E. (2001). Use of 14 C and 13 C Natural Abundances for Evaluating Riverine, Estuarine, and Coastal DOC and POC Sources and Cycling: a Review and Synthesis. Org. Geochem. 32, 469-485. doi:10.1016/ s0146-6380(00)00190-x

Schlitzer, R. (2018). Ocean Data View

Shang, P., Lu, Y., Du, Y., Jaffé, R., Findlay, R. H., and Wynn, A. (2018). Climatic and Watershed Controls of Dissolved Organic Matter Variation in Streams across a Gradient of Agricultural Land Use. Sci. Total Environ. 612, 1442-1453. doi:10.1016/j.scitotenv.2017.08.322

Stedmon, C. A., and Bro, R. (2008). Characterizing Dissolved Organic Matter Fluorescence with Parallel Factor Analysis: a Tutorial. Limnol. Oceanogr. Methods 6, 572-579. doi:10.4319/lom.2008.6.572b

Strokal, M., Yang, H., Zhang, Y., Kroeze, C., Li, L., Luan, S., et al. (2014). Increasing Eutrophication in the Coastal Seas of China from 1970 to 2050. Mar. Pollut. Bull. 85, 123-140. doi:10.1016/j.marpolbul.2014.06.011
Wang, B., Xin, M., Wei, Q., and Xie, L. (2018). A Historical Overview of Coastal Eutrophication in the China Seas. Mar. Pollut. Bull. 136, 394-400. doi:10.1016/ j.marpolbul.2018.09.044

Wang, Y., Liu, D., Dong, Z., Di, B., and Shen, X. (2012). Temporal and Spatial Distributions of Nutrients under the Influence of Human Activities in Sishili Bay, Northern Yellow Sea of China. Mar. Pollut. Bull. 64, 2708-2719. doi:10.1016/j.marpolbul.2012.09.024

Wetz, M. S., Cira, E. K., Sterba-Boatwright, B., Montagna, P. A., Palmer, T. A., and Hayes, K. C. (2017). Exceptionally High Organic Nitrogen Concentrations in a Semi-arid South Texas Estuary Susceptible to Brown Tide Blooms. Estuarine, Coastal Shelf Sci. 188, 27-37. doi:10.1016/j.ecss.2017.02.001

Yamashita, Y., and Tanoue, E. (2008). Production of Bio-Refractory Fluorescent Dissolved Organic Matter in the Ocean interior. Nat. Geosci. 1, 579-582. doi:10.1038/ngeo279

Yang, F., Song, G., Massicotte, P., Wei, H., and Xie, H. (2020). Depth-Resolved Photochemical Lability of Dissolved Organic Matter in the Western Tropical Pacific Ocean. J. Geophys. Res. Biogeosciences 125, e2019JG005425. doi:10.1029/ 2019jg005425

Zhang, J., and Yang, G. (2013). Chemical Properties of Colored Dissolved Organic Matter in the Sea-Surface Microlayer and Subsurface Water of Jiaozhou Bay, China in Autumn and winter. Acta Oceanol. Sin. 32, 26-39. doi:10.1007/ s13131-013-0306-4

Zhang, Y., Gao, X., Guo, W., Zhao, J., and Li, Y. (2018). Origin and Dynamics of Dissolved Organic Matter in a Mariculture Area Suffering from Summertime Hypoxia and Acidification. Front. Mar. Sci. 5, 325. doi:10.3389/ fmars.2018.00325

Zhang, Y., Yang, G., and Chen, Y. (2009). Chemical Characterization and Composition of Dissolved Organic Matter in Jiaozhou Bay. Chin. J. Ocean. Limnol. 27, 851-858. doi:10.1007/s00343-009-9020-7

Zhang, Y., Zhang, E., Yin, Y., Van Dijk, M. A., Feng, L., Shi, Z., et al. (2010). Characteristics and Sources of Chromophoric Dissolved Organic Matter in Lakes of the Yungui Plateau, China, Differing in Trophic State and Altitude. Limnol. Oceanogr. 55, 2645-2659. doi:10.4319/lo.2010.55.6.2645

Zhao, C., Zhou, Y., Pang, Y., Zhang, Y., Huang, W., Wang, Y., et al. (2021). The Optical and Molecular Signatures of DOM under the Eutrophication Status in a Shallow, Semi-Enclosed Coastal Bay in Southeast China. Sci. China Earth Sci. 64. doi:10.1007/s11430-020-9728-4

Zhao, W.-h., Wang, J.-t., Jiao, N.-z., and Zhao, Z.-x. (2001). Dissolved and Particulate Organic Carbon in Yantai Sishili Bay Aquiculture Waters. Chin. J. Ocean. Limnol. 19, 178-185. doi:10.1007/bf02863044

Zsolnay, A., Baigar, E., Jimenez, M., Steinweg, B., and Saccomandi, F. (1999). Differentiating with Fluorescence Spectroscopy the Sources of Dissolved Organic Matter in Soils Subjected to Drying. Chemosphere 38, 45-50. doi:10.1016/s0045-6535(98)00166-0

Conflict of Interest: The authors declare that the research was conducted in the absence of any commercial or financial relationships that could be construed as a potential conflict of interest.

Copyright $\odot 2021 \mathrm{Li}$, Zhao, Liu, Xiao, Wang, Wang and He. This is an open-access article distributed under the terms of the Creative Commons Attribution License (CC $B Y$ ). The use, distribution or reproduction in other forums is permitted, provided the original author(s) and the copyright owner(s) are credited and that the original publication in this journal is cited, in accordance with accepted academic practice. No use, distribution or reproduction is permitted which does not comply with these terms. 